ISSN 2179-345X

Licenciado sob uma Licença Creative Commons

\title{
Psicologia do testemunho
}

\author{
Psychology of the testimony
}

\begin{abstract}
Graziella Ambrosio
Especialista em Direito e Processo do Trabalho pela Faculdade de Direito da Universidade de São Paulo (USP), Mestranda em Direito das Relações Sociais pela Pontifícia Universidade Católica de São Paulo (PUC-SP), São Paulo, SP - Brasil, e-mail: gambrosio@bb.com.br
\end{abstract}

\section{Resumo}

O testemunho de uma pessoa sobre um fato depende, essencialmente, de como ela percebeu esse acontecimento, de como sua memória o armazenou e o evocou e, ainda, do modo como esse fato pode ser expresso. Sobre esses processos psíquicos (percepção, memória e expressão) atuam uma série de fatores externos e internos ao indivíduo, como hábito, automatismo, memória temporal e tendência afetiva. Nesse sentido, a análise prévia do tipo de personalidade e das relações afetivas da testemunha permite verificar se o testemunho será ou não imparcial. Em outras palavras, é desvendar a intenção do testemunho, que pode ser vingança, compaixão, afeto, egoísmo, etc., podendo o interrogador aplicar técnicas, como o método centrípeto, para obter o exato esclarecimento dos fatos. Embora nenhum testemunho seja perfeito, é possível aferir o grau de fidedignidade do relato da testemunha por meio dos instrumentos de análise psicológica.

Palavras-chave: Psicologia jurídica. Psicologia do testemunho. Testemunha. Psicologia. Prova testemunhal. 


\section{Abstract}

A personal testimony about a fact essentially depends in how she or he perceived such fact, in how her or his memory has been kept and remembered and yet, the way this fact can be expressed. On these psychological process (perception, memory and expression) are acting a series of external and internal factors to the individual, like habit, automatism, timing memory and affective tendency. Therefore, the previous analyses of witness' personality and affective relation allows a verification if the testimony will be or not impartial. In other words, it means uncover the testimony's intention, which can be revenge, compassion, sympathy, egocentrism, etc., allowing the interrogator to use techniques, such as the 'centripeto method', to obtain a exact clarifying of the facts. Although no one testimony is perfect, it is possible improve the trustworthiness of the witness report by means of psychological analyse's tools.

Keywords: Legal psychology. Psychology of the testimony. Witness. Psychology.

Oral testimony.

\section{Introdução}

O testemunho de uma pessoa sobre um acontecimento está calcado essencialmente no tripé: percepção, memória e expressão do fato. A seguir, analisaremos os principais fatores que afetam esses processos psíquicos e, consequentemente, a qualidade (exatidão e credibilidade) do testemunho.

\section{Percepção}

A percepção é o processo que consiste em atribuir significado às informações (experiências vividas) captadas pelo sistema sensorial que chegaram ao córtex cerebral (ATKINSON et al., 2002). Trata-se de uma experiência psíquica complexa e pessoal que sofre a influência de diversos fatores internos e externos ao observador. 
As pesquisas (MIRA Y LÓPEZ, 2009) revelam alguns resultados concretos quanto à percepção:

a) a capacidade de apreensão de estímulos é maior pela manhã do que à noite;

b) as mulheres percebem com mais exatidão os detalhes que os homens;

c) os acontecimentos iniciais e finais são melhor percebidos que os intermediários;

d) o testemunho sobre dados qualitativos é mais preciso do que sobre dados quantitativos;

e) as pessoas diferem entre si quanto à duração das vivências no tempo.

A percepção da realidade exterior é deformada pelas tendências afetivas de cada pessoa, como o desejo que um acontecimento se realize ou não ('sugestão da espera'). No caso dessa sugestão da espera, a consciência considera acontecido algo que ainda não ocorreu ou que ocorreu apenas em parte (MIRA Y LÓPEZ, 2009). Nesse sentido, o testemunho pode sofrer tanto a deformação voluntária e consciente do indivíduo como a distorção involuntária decorrente da afetividade própria da pessoa. Ainda que queira, a testemunha não consegue fugir à influência deformante da percepção dos fatos. Cada qual pode ver a realidade de modos diferentes, o que prova que o processo perceptivo está intimamente ligado à tendência afetiva de cada indivíduo.

A percepção é afetada também pelos automatismos mentais (hábito) presentes em toda pessoa e que impedem a testemunha de depor sobre a presença ou ausência de outros detalhes do fato que lhe passaram totalmente despercebidos (MIRA Y LÓPEZ, 2009). Além disso, o hábito faz com que a testemunha descreva os fatos mais como costumam acontecer do que como podem ter ocorrido na realidade. Por mais que queiramos não podemos subtrair-nos à ação de nossos automatismos mentais e, em virtude do hábito, completamos de tal modo as percepções da realidade 
exterior que basta que se encontrem presentes alguns de seus elementos para que nosso juízo de realidade se dê por satisfeito e aceite a presença do todo (MIRA Y LÓPEZ, 2009).

Embora o processo de percepção varie de pessoa para pessoa, em geral o automatismo mental faz com que as testemunhas tenham dificuldade para dizer a cor da roupa ou do sapato do envolvido no fato, se a pessoa trazia um anel, se havia mancha na roupa, se um objeto mudou de lugar, bem como se houve mudança de caráter ou de conduta pelas pessoas com quem se convive habitualmente, pois a menos que se focalize de forma intencional em uma determinada situação ou estímulo, a percepção tende a ser efetuada pelas lembranças que armazenamos dos acontecimentos.

Por isso, Mira y López (2009) afirma que o passado intervém mais do que o presente em nossas percepções e isso é tão certo que uma mudança de caráter ou de conduta pode ser notada antes pelas pessoas que não têm intimidade do que pelos parentes do indivíduo, uma vez que estes, por seu maior hábito em lidar com ele, levarão mais tempo em desligar-se do conceito que dele formaram, independentemente de que este seja bom ou mau.

O que uma pessoa recorda perfeitamente outra pode esquecer, pois a realidade nada mais é do que uma caricatura subjetiva (MIRA Y LÓPEZ, 2009). As pessoas que presenciaram certos fatos visualizam nuances dos acontecimentos que passariam despercebidas por outras (FIORELLI; MANGINI, 2009).

Além disso, tanto o estresse elevado quanto a violência tendem a diminuir a capacidade de captação das informações, pois a pessoa estava com a atenção voltada à própria defesa, o que também pode prejudicar a qualidade do testemunho. A mesma conclusão se aplica àqueles indivíduos que, no momento da percepção, estavam sob o efeito de substâncias químicas que afetam a consciência e, consequentemente, a apreensão da realidade. 


\section{Memória}

A memória refere-se ao conjunto de mecanismos psíquicos responsáveis pelo armazenamento das representações (de informações e experiências vividas), possibilitando sua fixação, retenção e posterior evocação (ATKINSON et al., 2002). O processo de armazenamento das informações é somente influenciado por condições orgânicas (MIRA Y LÓPEZ, 2009), ao passo que o processo evocador (reconstrução na mente da experiência vivida) é direta e profundamente influenciado pelas tendências afetivas.

O processo de memória humana é complexo e compreende uma rede de relações entre o evento, o contexto, o estado de espírito e o conhecimento do observador a respeito dos fatos que ocorreram (ROVINSKI, 2009). Durante o processo de armazenamento, as informações e representações continuam a sofrer atuação de outros fatores, como as crenças, padrões, experiências vividas, novas informações, dentre outros.

Desde muito é conhecida a chamada amnésia emocional, que se observa como decorrência de um profundo abalo emocional e que torna a pessoa incapaz de se lembrar da situação perturbadora. Em geral, as pessoas tendem a esquecer acontecimentos que estejam relacionados a emoções desagradáveis ou dolorosas (ódio, horror, remorso, etc.), funcionando o esquecimento como defesa psíquica.

O esquecimento ainda pode derivar da repressão quando fatos e acontecimentos são expulsos da consciência. Quando ocorre a repressão (processo inconsciente), a evocação das lembranças se faz de maneira distorcida e incompleta, afastando em muito os fatos da realidade, pois a tendência natural do indivíduo é complementar essas lembranças fragmentadas com associações lógicas que já se encontram em seu psiquismo.

Mira y López (2009) explica que a repressão, na grande maioria das vezes, age de modo fragmentário, não suprimindo, mas dificultando a evocação das lembranças. Então estas surgem incompletas, deformadas e misturadas com falsas lembranças que são produto da ação do mecanismo catatímico, continuada mesmo depois do fato perceptivo. E o indivíduo, quando se dá conta da pobreza de suas lembranças, as completa 
automaticamente, utilizando as cadeias de associações que logicamente devem se encontrar relacionadas com eles, e isso faz com que, mesmo estando de absoluta boa-fé, o resultado da evocação se acha tão distante da realidade como o poderia estar o sonho (MIRA Y LÓPEZ, 2009).

Nesse sentido, se considerarmos que os depoimentos, em regra, envolvem uma carga emocional intensa, compreende-se a constância com que a amnésia emocional se apresenta não só nos autores, como nas testemunhas. Em situações de emoção profunda de nada adianta o juiz forçar ou ameaçar a testemunha para prestar esclarecimentos sobre determinados fatos, pois os detalhes podem ter sido esquecidos involuntariamente.

Acreditam os juízes que quanto mais emotiva e intensa for a situação, mais a testemunha se recordará dos detalhes do fato, mas o que ocorre é justamente o inverso, pois o que se observa é a atuação de mecanismos psíquicos inconscientes do indivíduo que impõem o esquecimento de fatos traumáticos e dolorosos. Nessas condições, quanto mais esforço fizer a testemunha para vencer esse esquecimento, mais firme este se tornará.

Fiorelli (2010) resume com percuciência os efeitos dos estados emocionais sobre a memória:

a) recuperação lacunar das informações (a mente elimina conteúdos que trariam dor ou desconforto);

b) ampliação de atributos (recorda-se de algo ruim como pior do que realmente foi e de algo de bom como extremamente melhor);

c) fixação das recordações nos aspectos desagradáveis dos acontecimentos;

d) distorção da interpretação dos acontecimentos, por omissão de aspectos relevantes, ampliação de detalhes pouco significantes ou combinação desses elementos;

e) desvanecimento dos traços de memória com o passar do tempo;

f) interferências entre conteúdos, os relatos misturam eventos e suas consequências; 
g) incorporação de fantasias às recordações, particularmente nas narrativas de graves conflitos que se prolongaram por muito tempo;

h) preenchimento de hiatos de memória com suposições plausíveis, fenômeno corriqueiro mesmo em narrativas de incidentes sem maiores consequências.

Outro fator que atua diretamente na evocação das lembranças é o lapso temporal decorrido entre o fato e o testemunho, verificandose uma diminuição no grau de retenção das informações à medida que o tempo passa. Assim, quanto mais tempo transcorreu, menos preciso tende a ser o testemunho. A idade da testemunha também influencia esse processo, chegando-se a afirmar que nem as crianças, nem os velhos são testemunhas dignas de confiança (MIRA Y LÓPEZ, 2009). As crianças são extremamente sugestionáveis e os idosos tendem a se recordar mais facilmente do passado remoto do que do passado recente.

\section{Expressão do fato}

Quanto à expressão do testemunho, são raras as pessoas que conseguem observar com precisão os fatos, mantê-los exatos em sua mente e reproduzi-los com fidelidade por meio do processo da evocação voluntária. Em geral, os indivíduos não possuem inteligência verbal (MIRA Y LÓPEZ, 2009) para exprimir de forma exata suas vivências. São poucas as pessoas que conseguem descrever bem em palavras tudo quanto perceberam da realidade exterior. Por essa razão, o julgador deve intervir o mínimo possível no depoimento da testemunha, pois toda resposta ou é imantada pelas tendências afetivas do interrogado ou é produto de lembranças fragmentadas, preenchidas por deduções lógicas do indivíduo, ou, ainda, é equivocada em razão do medo sentido pela testemunha com a pergunta.

Também afetam a expressão do fato, o ambiente do interrogatório, os tipos de perguntas e a linguagem usada entre interrogador e 
testemunha. Se o ambiente da sala de audiências se apresenta desagradável até para operadores do Direito, para aqueles que não estão acostumados ao meio forense, esse ambiente se apresenta ainda mais ameaçador. Assim, a qualidade do testemunho passa pela existência de um ambiente tranquilo, onde a testemunha se sinta acolhida para relatar os fatos que presenciou.

Outro obstáculo à expressão do fato pode ser a linguagem utilizada pelo interrogador. É comum a utilização em interrogatórios de expressões e construções linguísticas próprias do Direito, mas tal prática é desaconselhável, pois pode inibir ou confundir a testemunha. É recomendável a utilização de expressões e palavras de fácil entendimento para a testemunha, estando o interrogador sempre atento ao grau de maturidade e experiência da pessoa. Detalhes técnicos devem ser exigidos apenas dos profissionais da área e jamais de pessoas leigas no assunto, até porque aqueles têm mais facilidade de observar e reter detalhes atinentes ao seu campo de especialização.

O desequilíbrio emocional acentua-se quando a testemunha não encontra a melhor forma de se expressar, ou seja, não concatena as ideias ou as palavras lhe fogem à mente (FIORELLI, 2010). Uma testemunha desequilibrada e fragilizada é potencial vítima de manipulação pela parte interessada, devendo o interrogador estar atento a esse fato e não permitir a exploração do testemunho com vistas à distorção da realidade dos fatos pela pura emoção do observador.

Uma boa estratégia para o interrogador é valer-se do silêncio (TRINDADE, 2009), aguardando que a própria testemunha inicie ou prossiga seu depoimento, pois o relato espontâneo tende a ser menos deformado, tendo em vista que gera menos conflito, além do que, normalmente, revela a linha de pensamento da testemunha, permitindo ao interrogador descobrir o que está por trás de seu testemunho.

Mira y López (2009) esclarece que o relato espontâneo tende a ser menos deformado que o obtido por interrogatório, mas pode se apresentar, por outro lado, irregular ou incompleto e até fornecer dados inúteis para o processo. Já o testemunho obtido por interrogatório costuma fornecer dados mais concretos, porém menos exatos, via de regra, que os 
do relato espontâneo, pois é o resultado do conflito entre o que o indivíduo sabe, de um lado, e o que as perguntas que se lhe dirigem tendem a fazê-lo saber.

Por outro lado, deve o interrogador estar atento à linguagem não verbal da testemunha, como olhares, gestos, rubor da pele, suor, mãos trêmulas, movimento das pernas e pés, postura, etc. Esses sinais externos da testemunha podem auxiliar o interrogador para detectar se ela realmente conhece os fatos, se foi instruída a depor ou se está mentindo. A fala e os gestos ainda podem denunciar crenças arraigadas e esquemas de pensamento (ex: sindicalista não é confiável; empregador é desonesto; isso é coisa de mulher; todo homem é safado) que afetam o testemunho do indivíduo, pois atuam diretamente na interpretação dos fatos presenciados.

As perguntas que iniciam com pronomes interrogativos (ex: Como? Quando? Onde? Quem? Por quê? O quê?) são as mais indicadas, pois são consideradas imparciais (MIRA Y LÓPEZ, 2009). Perguntas que induzem a testemunha a responder conforme esperado pelo interrogador, ou que partem do pressuposto que a testemunha já conhece outros fatos ou, ainda, impõem ao depoente decidir entre duas opções com exclusão de todas as outras, devem ser evitadas, pois acarretam maior inclinação para o erro pela testemunha.

Chehab (2009), baseado nas lições de Trindade (2009), ensina que perguntas argumentativas, desacreditadoras, insinuadoras e sugestivas, via de regra, devem ser indeferidas pelo interrogador, pois tencionam conduzir, desqualificar ou desequilibrar emocionalmente a testemunha. Da mesma forma, questões confrontadoras podem ser indeferidas dependo do tom ou do modo em que forem feitas, ao passo que perguntas interpretativas, normalmente, não são muito úteis ao deslinde da controvérsia e questionamentos exploratórios podem ser necessários para aferir o grau de conhecimento da testemunha sobre o fato (CHEHAB, 2009).

Cabe destacar, no entanto, que pessoas imorais ou amorais não se intimidam com o ambiente da sala de audiências ou com a forma como são elaboradas as perguntas, nem com as características do interrogador. Mira y López (2009) esclarecem que as testemunhas mais morais são 
precisamente as que costumam impressionar-se mais diante das ameaças e da severidade e cerimonial que se desenvolvem durante o interrogatório, ao passo que os imorais ou amorais não reagem nem pouco nem muito perante ele. Tais indivíduos, segundo esses autores, não se impressionam diante de ameaças no interrogatório, nem com o cerimonial do ambiente forense. Quanto a essas testemunhas de pouca valia, é necessária a análise da linguagem não verbal, pois será muito difícil ao interrogador identificar se o depoente está mentindo.

\section{Fidedignidade do testemunho}

Mais do que qualquer juramento ou advertência sobre a responsabilidade do testemunho, é a análise prévia do tipo de personalidade e das relações afetivas da testemunha que permitirá verificar se o testemunho é ou não imparcial. Em outras palavras, é desvendar a intenção do testemunho, que pode ser vingança, compaixão, afeto, amizade, egoísmo, etc.

Se a testemunha estiver imbuída de sentimentos nobres, como o afeto, a generosidade ou a compaixão, deverá o interrogador criar nela a convicção de que um depoimento parcial poderá prejudicar a pessoa a quem pretende beneficiar. Deve o interrogador advertir que o melhor é dizer a verdade exata quando do esclarecimento dos fatos, pois uma pequena mentira, proferida no afã altruísta, pode colocar em descrédito toda a descrição verdadeira dos fatos.

Outra opção é o interrogador se abster de fazer perguntas diretamente relacionadas ao acusado ou à conduta delituosa, limitando-se a questionar sobre os chamados fatos secundários (método centrípeto), no intuito de desvincular a testemunha de sua intenção nobre para com o acusado e, assim, obter um caminho para o esclarecimento dos fatos principais.

Pela elucidação desses fatos secundários é possível saber, por exemplo, a motivação do acusado, ou seja, seu estado interno (de natureza afetiva e cognitiva), que o mobiliza a agir (comportamento) com a finalidade de atingir um objetivo, ou, ainda, traços de sua personalidade 
(ambição, desejo de riqueza, timidez, força de vontade, etc.), pois perguntas afastadas do acusado permitem que a intenção do questionamento fique mascarada (MIRA Y LÓPEZ, 2009), impedindo que a testemunha oriente suas respostas a favor ou contra o acusado.

Além de compreender os interesses, intenções, sentimentos e processos inconscientes que interferem no testemunho, o interrogador deve perceber que muitas testemunhas necessitam se sentir protegidas no ambiente da sala de audiências, enquanto, para outras, uma conversa prévia ao depoimento é suficiente para libertá-las de eventuais medos e receios. A figura do juiz desperta no imaginário popular sentimentos de respeito, receio e admiração, tal fato deve ser percebido pelo magistrado e utilizado, com outros mecanismos psicológicos, para não aumentar ainda mais o desequilíbrio emocional da testemunha.

Por fim, deve o interrogador tomar cuidado para pedir à testemunha apenas a descrição dos fatos e não a interpretação deles. Isso porque a eventual interpretação dos fatos pela testemunha exigiria um exame de sua capacidade de julgamento intelectual e moral (MIRA Y LÓPEZ, 2009), sendo comum não apenas os erros de observação e lembrança, como as interpretações erradas dos fatos. Cabe lembrar que a testemunha é a pessoa que presencia um fato, não devendo fazer juízos de valor sobre esses fatos em seu depoimento.

\section{Considerações finais}

Um testemunho só pode ser valorado conhecendo quem o fez. Isso porque o tipo de personalidade, os hábitos e as tendências afetivas da testemunha afetam decisivamente a elucidação feita por ela sobre os fatos. Disso resulta que nenhum testemunho é perfeito, mas por meio dos instrumentos de análise psicológica é possível aferir o grau de fidedignidade do relato da testemunha.

O testemunho pode conter erro de percepção (decorrente de tendências afetivas, distorções psíquicas involuntárias, automatismos mentais, 
estresse, violência), erro de memória (decorrente de condições orgânicas, estado de espírito do observador, crenças, novas informações, emoções dolorosas, repressão) e erro de expressão (decorrente de falta de inteligência verbal, do ambiente da sala de audiência, dos tipos de perguntas, da linguagem usada entre interrogador e testemunha).

Embora não caiba à testemunha fazer juízos de valor sobre os fatos, processos na maioria das vezes inconscientes afetam a captação, o armazenamento e a exteriorização das informações e representações. Esses diversos fatores de ordem psicológica influenciam diretamente na qualidade do testemunho.

Todo evento presenciado passa pelo filtro interpretativo de cada pessoa e é composto por seus conhecimentos prévios, sentimentos e expectativas. E as interferências não param por aí. No processo de armazenamento dessas lembranças, também atuam fatores de ordem interna e externa, como os comentários de outras pessoas sobre o acontecimento, a mídia, novas informações. Por fim, na reconstrução do fato a testemunha tende a preencher eventuais lacunas com informações já existentes em seu psiquismo e que podem não estar relacionadas à realidade dos acontecimentos.

Ao Direito interessa a realidade efetiva dos fatos, mas nem sempre esta guarda relação direta com a realidade psíquica das testemunhas. Um mesmo fato pode gerar diferentes interpretações, pois cada indivíduo possui uma visão particular de mundo. $\mathrm{O}$ que a mente percebe e retém dos acontecimentos depende de fatores internos e externos. Podemos considerar fatores internos o próprio aparelho sensório de cada pessoa, que é imperfeito, como os conteúdos emocionais preexistentes dos indivíduos, que, em sua maioria, escapam à consciência do indivíduo. E, como fatores externos, o contexto social e cultural que se combina com aqueles fatores internos para formar a realidade psíquica de cada um. Mas isso não significa que a utilização dos instrumentos de análise psicológica não possa favorecer a compreensão da verdade real perseguida pelo Direito.

Embora a prova testemunhal seja o meio mais inseguro, em muitos processos se constitui o principal fundamento da decisão que dirime a controvérsia. Nesse sentido, entender a extensão com que ocorrem as 
interferências emocionais sobre o testemunho aumenta as chances de melhor lidar com a testemunha e obter dela um relato fático que seja mais próximo possível da realidade.

\section{Referências}

ATKINSON, R. L. et al. Introdução à psicologia de Hilgard. 13. ed. Porto Alegre: Artes Médicas, 2002.

CHEHAB, G. C. A psicologia do testemunho no processo do trabalho. Revista Trabalhista Direito e Processo, Brasília, v. 8, n. 30, p. 112-123, 2009.

DAVIDOFF, L. L. Introdução à psicologia. 3. ed. rev. e amp. São Paulo: Makron Books, 2001.

FIORELLI, J. O. Psicologia aplicada ao direito. Revista do Tribunal Regional

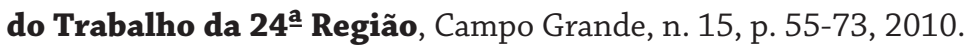

FIORELLI, J. O.; MANGINI, R. C. R. Psicologia jurídica. São Paulo: Atlas, 2009. MIRA Y LÓPEZ, E. Manual de psicologia jurídica. São Paulo: Vida Livros, 2009. ROVINSKI, S. L. R.; CRUZ, R. M. (Org.). Psicologia jurídica: perspectivas teóricas e processos de intervenção. São Paulo: Vetor, 2009.

TRINDADE, J. Manual de psicologia jurídica para operadores do direito. 3. ed. Porto Alegre: Livraria do Advogado, 2009.

Recebido: 01/03/2011

Received: 03/01/2011

Aprovado: 05/04/2011

Approved: 04/05/2011 